\title{
Partial Locked-In Syndrome: A Case Study and Reflections on Assessment
}

\author{
Barbara A Wilson*, Hannah Potticary, Andy Weare and Anita Rose \\ Department of Neuropsychology, The Oliver Zangwill Centre for Neuropsychological Rehabilitation, United Kingdom \\ *Corresponding Author: Barbara A Wilson, Department of Neuropsychology, The Oliver Zangwill Centre for Neuropsychological \\ Rehabilitation, United Kingdom.
}

Received: July 09, 2019; Published: August 27, 2019

\begin{abstract}
We describe the case of Andy, a man with partial Locked-In Syndrome and consider the definition of LIS, reporting that at least 60 per cent of people with this condition have sustained a stroke in the area of the pons. We reflect on the best way to determine the cognitive functioning of people with LIS and whether or not their cognitive abilities are normal. We also address the issue of assessments when people have both LIS and cortical damage. Andy, the patient, provides his own views on what it is like to have partial LIS. We conclude that his cognitive functioning is, on the whole, good apart from one test of visual problem solving. In fact two other patients assessed in detail by us show the same pattern. The main difference between Andy and the others is that he sees no advantages in having LIS whereas the two previously reported patients both found positives in their condition.
\end{abstract}

Keywords: Locked-In Syndrome; Assessment

\section{Introduction}

Locked-In Syndrome (LIS) is a rare consequence of brain damage whereby patients are fully conscious but unable to move or speak due to paralysis of nearly all voluntary muscles except the eyes. Most LIS patients have sustained a stroke in the basilar artery or suffered a pontine haemorrhage [1]. Schnakers., et al. [2] believe that at least 60 per cent of LIS patients have sustained this type of damage. Even so, LIS probably represents less than one per cent of all strokes [3]. In 1995, The American Congress of Rehabilitation Medicine noted that LIS had five characteristics, namely (i) sustained eye opening (ii) preserved basic cognitive abilities (iii) aphonia or severe hypophonia (loss of voice) (iv) quadriplegia or quadriparesis and $(\mathrm{v})$ vertical or lateral eye movement or blinking of the upper eyelid as the primary means of communication.

Wilson, Dhamapurkar and Rose [4] discuss the issue of preserved basic cognitive abilities and note that although people with LIS are relatively unimpaired cognitively, some minor cognitive diffi- culties may be apparent. Schnakers., et al. [2] believe that "additional brain injuries are most likely responsible for associated cognitive deficits in LIS"(p233).

Such difficulties are detected through neuropsychological testing. Although people with LIS cannot perform motor tests or tests which require spoken responses, there are many tests which can be administered. These include tests where the response is through eye pointing, blinking, spelling out through eye gaze or use of a computerised communication system. Several studies have described neuropsychological assessment of people with LIS and these are described by Wilson., et al [4]. The most detailed assessment recorded is probably that of Wilson, Hinchcliffe, Okines, Florschutz and Fish [5]. This was the case of a young woman who developed LIS after a fall at the gym which caused a pontine tear leading to a brain stem stroke.

Although communication with people with LIS is slow, it is not difficult once the system is worked out. Many people with LIS use 
this pattern was also seen in the two patients with LIS assessed in detail by the first author [4,5]. All three patients, namely Andy and the two previously published patients had essentially normal cognitive functioning as measured by the tests with some minor problems on certain tasks namely visual processing, organisation and reasoning tasks. Their basic vision was obviously unimpaired as they were able to do visuo-perceptual tasks with little difficulty. Smith and Delargy [16] remind us that visual problems are not uncommon. On the SF-36, Andy reported that, during the past four weeks, he has accomplished less than he would like, was limited in activities and had difficulty performing activities. He further reported that, in the past four weeks, his physical or emotional problems have interfered with his social activities most of the time. However, Andy rated himself as having fewer health problems overall compared to one year ago.

\section{Personal perspectives from Andy}

Andy was asked what he missed because of his stroke. He replied "Driving my Jet ski and playing golf". He said his hopes for the future were "To live independently". We wondered what he thought about when he was alone to which he spelled out "How long I will be in here [hospital] and my progress". Are there any positives to having LIS, we said to Andy. He did not think there were any positives. He thought the worst part of his situation was feeling "useless". When asked what he thought the best things in life are now, Andy said "My family". He is a father and grandfather with many photos of his children and grandchildren on the wall of his room.

\section{Discussion}

Is the diagnosis of partial LIS correct for this man? His lesion, in the medulla, is part of the brain stem as is the pons, the lesion responsible for LIS. Thus Andy"s lesion is adjacent to that causing full blown LIS. The brain stem provides the main motor and sensory nerve supply to the face and neck. The fact that Andy's is spared may explain why he has facial expression, head movement and a little movement in his left hand. Many of the cranial nerves originate in the Pons including the trigeminal nerve which aids facial sensation, movement and expression and the abducent nerve aids eye movement.

Also, another primary function of the pons is to connect the forebrain with hindbrain connecting the cerebrum to the cerebe- llum through the cerebral peduncle. The cerebral peduncle is the anterior portion of the midbrain that consists of large nerve tracts. The pons relays sensory information between the cerebrum and cerebellum. Functions under the control of the cerebellum include fine motor coordination and control, balance, equilibrium, muscle tone, fine motor coordination, and a sense of body position. Laureys (personal communication) believes Andy has partial LIS because his main communication is with his eyes even though he has some movement.

Like others with LIS, Andy has essentially normal cognitive functioning. His only difficulty with testing was with a non-verbal problem solving test. We have said before that some minor cognitive problems may be seen in people with LIS. This may be due to sensory difficulties such as poor eyesight or to other brain lesions. Thus, Andy is similar to others reported. He rates his QoL as reasonable despite having severe physical impairments. He is not depressed or stressed and only has mild anxiety.

Where Andy differs from the two patients described by Wilson., et al. $[4,5]$ is that he can think of no positives to having LIS. Tracey [5] said "I see things differently. I don't get angry by things any more. On the grand scale things really don't matter" (p535). Paul [4] reflected that "there is a positive aspect to my stroke: it has given me plenty of time to examine myself and decide how I could improve" (p34). Andy doesn't feel this way and this may be because Andy's family live far away whereas both the others had close links with their families and saw them almost every day.

\section{Conclusions}

The majority of people with LIS have sustained a mid brain stroke. Communication with them is slow but not difficult. It is possible to assess their cognitive abilities although motor tests and tests of speed have to be avoided. Some people have LIS plus cortical damage which can make diagnosis a problem. This was not true of Andy. We report the case of Andy, a man with partial LIS. We believe it is partial because he has facial expression and a little movement. His cognitive functioning is generally good and similar to other patients who have been neuropsychologically assessed. He sees no positives in his condition, however, unlike others we have seen. 
eyes up for yes and down for no, others use a chart system whereby the letters are read out and the person blinks when the right letter is sounded. Some use a computerized system whereby they look at the letter or word they want to say and this then appears on the screen. Another communication system is an E-Tran frame. This is a sheet of stiff, transparent plastic with letters, symbols or words stuck on. The person with LIS gazes at the letter, symbol, or word they want to say.

There are times, however, when diagnosis is unclear. The assessor is not sure whether or not the person has LIS. Mistry, Wilson and Rose [6] discuss the issue of assessing people who have the correct lesion for LIS to occur but who have additional cortical damage perhaps with language impairments. Some have problems with eye control (ophthalmoplegia) making it difficult for them to control their eye muscles. Other diagnostic problems may occur when there is more ability than some people expect for a diagnosis of LIS. The young woman reported in Wilson., et al. [5], for example, was considered by some staff working with her, that she did not have LIS because she could communicate with her eyes when she needed to open her bladder or her bowels so she was not incontinent. In fact she had a classic LIS fulfilling all criteria laid down by the American Congress of Rehabilitation Medicine [7].

What happens when there is more movement than one would expect? The fourth of the five criteria mentioned above says "quadriplegia or quadriparesis" that is paralysis or weakness so some movement can occur in some people with LIS. The case we report here is said to have partial LIS because he has good facial expression and head movement plus a little movement in his left hand. Other than that, he fulfills the American Congress of Rehabilitation Medicine [7] criteria.

\section{Case Report of Mr Andy Weare}

Andy, a former lorry driver, sustained a stroke on November $2^{\text {nd }}$ 2017 at the age of 54 years. He was admitted to hospital with a frontal headache, dysphagia and expressive aphasia. An MRI scan showed left vertebral artery thrombotic occlusion, with thrombolysis and further ischaemia in the left posterior, inferior, cerebellar artery (PICA) territory and a left hemi medulla infarct. More ischaemia occurred on November $16^{\text {th }} 2017$. It proved difficult weaning him from a ventilator. He was admitted to the Raphael Hospital just over one year later and was seen for a neuropsychological assessment. It was noted that he was oriented in time, place and person and had no apparent cognitive deficits. It was felt that this needed to be confirmed.

Andy was easy to communicate with, since he presented with adequate head movement so was able to effectively answer yes and no questions with ease. He also communicated with a computer; he looked at the right letter and this appeared on a screen. When a word was complete the computer said the word. This means of communication, however, was slow and tiring for him. He sometimes made an error and the wrong letter or word would appear on the screen so that he would have to start the whole process again. The best system to use when responses required more than yes or no, was the E-Tran frame, a stiff sheet of Perspex with symbols or words stuck onto it. The communicator looks at the correct letter or word. One person would hold the frame and say the letter that Andy was indicating (he confirmed with a nod of the head) and the second person wrote this down. He was usually seen in his wheelchair in his bedroom for approximately 30 minutes at a time. He fatigued easily so assessment sessions had to be no longer than 30 minutes.

\section{Tests administered}

The Spot-the-Word test [8] was used to estimate Andy's premorbid IQ. This involves the presentation of pairs of words, one pair at a time. One of each pair is a real word and one is a made up word. The testee is required to indicate the real word each time. The Putney Auditory Comprehension Screening Test [9] was administered to check Andy's comprehension. A series of statements are read aloud and the person indicates whether the statement is true or false. A 64 item naming test was used to assess naming ability. Two recognition memory tests were given from the Rivermead Behavioural Memory Test-3 [10]. One was a picture recognition subtest and the other a face recognition subtest. The Autobiographical Memory Interview [11], a semi-structured interview, determined if there were particular time periods which caused difficulty for Andy. The Ravens Coloured Matrices [12] was used to assess non-verbal problem solving and the Visual Object and Space Perception Battery [13] was administered to check for problems with visual perception and visual spatial tasks. He was also given the Short Form (36) Health Survey (SF-36) to measure his quality of life [14] and the Depression Anxiety Stress Scales [15] to determine his mood.

\section{Test Results}

Andy's scores were in the normal range for all tests apart from the Ravens Coloured Matrices where he struggled. Interestingly 


\section{Bibliography}

1. Plum F and Posner JB. "The Diagnosis of Stupor and Coma". Davis, F.A., Philadelphia, PA (1983).

2. Schnakers C., et al. "Cognitive function in the locked-in syndrome". Journal of Neurology (2008) 255 (2008): 323-330.

3. Beaudoin N and De Serres L. "Locked-in Syndrome". In: JH Stone, M Blouin, editors. International Encyclopedia of Rehabilitation (2010).

4. Wilson BA., et al. Surviving Brain Injury After Assault: Gary's Story Hove: Psychology Press (2016).

5. Wilson BA., et al. "A case study of Locked-In Syndrome: Psychological and personal perspectives". Brain Injury 25 (2011): 526-538.

6. Mistry N., et al. "Challenges when diagnosing locked-in syndrome following TBI: The Story of U.P. a Clinical Puzzle". Journal of Clinical Review and Case Reports 4 (2019): 1-3.

7. American Congress of Rehabilitation Medicine. "Recommendations for use of uniform nomenclature pertinent to patients with severe alterations of consciousness". Archives of Physical Medicine and Rehabilitation 76 (1995): 205-209.

8. Baddeley AD., et al. The Speed and Capacity of Language Processing Tests Bury St Edmunds: Thames Valley Test Company (1992).

9. Beaumont JG., et al. The Putney Auditory Comprehension Screening Test Bury St Edmunds: Thames Valley Test Company (2002).

10. Wilson B.A. Greenfield E, Clare L, Baddeley A.D, Cockburn J, Watson P, Tate R, Sopena S \& Nannery R. The Rivermead Behavioural Memory Test -3 Pearson Assessment, London.

11. Kopelman M., et al. "The Autobiographical Memory Interview". Bury St Edmunds: Thames Valley Test Company (1989).

12. Raven, J., et al. "Manual for Raven's Progressive Matrices and Vocabulary Scales". San Antonio, TX: Harcourt Assessment (2004).

13. Warrington EK and James M. The Visual Object and Space Perception Battery Bury St Edmunds: Thames Valley Test Company (1991).
14. Ware JJr and Sherbourne CD. "The MOS 36-Item Short-Form Health Survey (SF-36): I. Conceptual Framework and Item Selection". Medical Care 30 (1992): 473-483.

15. Lovibond SH and Lovibond PF. "Manual for the Depression Anxiety Stress Scales". (2nd ed.). Sydney: Psychology Foundation (1995).

16. Smith E and Delargy M. "Clinical review: Locked-in syndrome”. British Medical Journal 330 (2005): 406-409.

\section{Volume 2 Issue 9 September 2019}

(c) All rights are reserved by Barbara A Wilson., et al. 